Diánoia, vol. 8, no. 8, 1962

\title{
EL CONOCIMIENTO DEL BIEN EN PLATÓN
}

Toda la filosofía, de acuerdo con Whitehead, es una apostilla a la obra de Platón. Esto es aplicable especialmente a la filosofía moral. Sin embargo, por extraño que parezca, nunca se ha desenvuelto uno de los indicios más prometedores de la solución que da Platón al problema de la filosofía moral.

La filosofía moral de Platón se desarrolla en cuatro etapas, que parten desde la pregunta "¿qué cosas son buenas?" hasta llegar a la pregunta "¿qué es lo bueno en sí mismo?"

\section{Primera etapa: El problema-La ciencia del bien}

La primera etapa es preparatoria y consiste en definir el problema: ¿Qué es lo que importa en la filosofía moral, saber qué cosas son buenas o saber qué es lo bueno en sí mismo? La respuesta a esta pregunta constituye la búsqueda hecha por Platón para encontrar una definición del valor, que al final nos llevará a una ciencia de los valores. Esta etapa está representada por los diálogos socráticos. Se refieren al primer nivel del análisis, o sea la transición del mundo empírico al mundo de los valores. Su método es dialéctico -de preguntas y respuestas. El diálogo que da culminación a esta etapa es el Protágoras, en el que se llega a una definición del bien y se pasa a un análisis de su naturaleza. El bien es el conocimiento. ¿Puede ser objeto de enseñanza? ¿Es comunicable? ¿Cuál es la relación entre la bondad moral y la aptitud? ¿Cómo se desarrolla la moral en la sociedad humana? ¿Cuál es la relación entre el bien y el placer, y otras cosas empíricas?

Esta etapa termina con el conocimiento intimo de que el bien no es algo empírico, sino un proceso racional. De esta manera, el problema consiste en saber cuál es la relación entre las cosas empíricas y este bien abstracto. ¿Puede conocerse el bien como se conocen las cosas, y cuál es la relación entre el conocimiento del bien y el conocimiento de las cosas? ¿Puede haber una ciencia del bien, como hay una ciencia de las cosas? "La idea del bien le llegó [a Sócrates] razonando en una forma completamente distinta [de la idea de Dios, que le impartió la religión griega]. Es el resultado de la búsqueda socrática de una definición de la virtud ética y de los fines sociales, que siempre se estrellan porque los interlocutores nunca pueden descubrir la sanción que convierte a la virtud o el fin propuesto en algo bueno y deseable." 1 Sócrates se dedicó a "las definiciones de 'la belleza', 'la bondad', 'la grandeza', etc., como cualidades que se observan en diversas clases de cosas materiales bellas,

1 Introducción a La República de Platón, de Paul Shorey, Loeb Classical Library, Cambridge, Mass., 1946, tomo II, pág. xxvii. 
buenas y grandes","2 porque "estaba desilusionado de la seguridad de que el universo funciona del mejor modo posible" 3 como había esperado encontrarlo en la teoría de Anaxágoras sobre la mente como la causa de todo. Pero esa teoría no llevaba a ninguna parte y Sócrates se dio cuenta de que el reino de lo empírico no podía encontrar la naturaleza de los valores. Ésta podía hallarse únicamente en el reino de la lógica; sobre las definiciones de lo que se propone que sean las palabras que representen valores, se puede cimentar "la erección de hipótesis más elevadas". 4 En esta forma "creó una ciencia nueva, tomándola de una teoría reconocida de 'ideas' o 'formas', surgidas de la reflexión acerca de la cualidad predicada cuando decimos 'este hombre es bueno' y que da como postulado alguna realidad segura tras los objetos fugitivos de lo sensible. Su método 'hipotético', bien conocido de los matemáticos, alcanza su culminación y mayor significado en La República.'.5

Según Platón, esta ciencia del bien era la única auténtica. Las "ciencias naturales", por ejemplo, aquellas a que se refiere el Timeo _la física, la biología y la patología-, "son precisamente las ramas de estudio menos 'científicas' en el sentido estricto de la palabra, ya que se refieren a objetos sensoriales". ${ }^{6}$ Lo que Platón llamó ciencia fue la ciencia del bien, la ciencia del valor: la filosofía moral.

El bien de que se ocupó Platón fue el de los valores en general, y no el valor de cosas determinadas. "El Bien es el valor en general, del cual la virtud moral es sólo un caso concreto. Tenemos ante nosotros la teoría de los valores, no la ética. . La ética no es una ciencia definitiva: se ocupa de valores concretos y formula hipótesis acerca de ellos. Éstos necesitan alcanzar validez mediante un estudio de principios definitvos, y ése es el estudio del bien, como tal." 7 Ese estudio se llama hoy Axiologia.

"El valor es independiente, tanto del deseo como de la naturaleza; en conexión con el Bien, el deseo puede ser juzgado y criticado. Así, todo el campo, no sólo de los seres temporales, sino también de los eternos, puede valorizarse aplicando la norma del Bien. En este sentido el Bien es diferente del Ser. El Bien es una norma del Ser. El Bien no es un Bien definido, a menos que se especifiquen las entidades particulares y las circunstancias especiales a que se adaptan de una manera determinada, de acuerdo con un principio general. Es como una fórmula algebraica, cuya expresión varia, de acuerdo con los diferentes valores dados a los elementos variables. No existe

2 Introducción general al Eutifrón de Platón, por W. R. M. Lamb, Loeb Classical Library, Cambridge, Mass., 1953, pág. $x$.

3 Ibid.

4 Ibid.

5 Ibid., pág. xi.

6 Introducción al Timeo, por R. G. Bury, Loeb Classical Library, 1952, pág. 14.

7 The Philosophy of Plato, por Raphael Demos, New York, 1939, pág. $4^{8}$ sigs. Véase también Plato's Theory of Ideas, por Sir David Ross, Oxford, 1951, págs. 42 sigs. 
un bien general; cada artefacto y cada cosa viviente tiene su propia naturaleza específica y su propio Bien específico (República 353 C, 441 E; Gorgias, $506 \mathrm{E}$ ). La virtud de un cuchillo es cortar; la de una mano es manejar. El bien del hombre incluye la sabiduría, en tanto que el del perro no la incluye. $O$, para hablar con mayor exactitud, hay un bien general y un bien particular. El bien de todo aquello en lo que hay semejanza es la autosuficiencia, la plenitud y la medida; y también el bien de todo es diferente, porque las condiciones generales producen resultados diferentes al aplicarse a diferentes situaciones... Tenemos generalidad de principio con variedad en su aplicación. De esta manera, el bien es tanto absoluto como relativo, tanto el bien simpliciter como mi propio bien (República 352 E, 353 A, B)... Sería un error considerar los cuatro elementos (la deseabilidad, la autosuficiencia, la plenitud y la medida) como una definición del Bien. El Bien es algo simple e indefinible; por lo mismo, no consiste en estas características; de hecho, el Bien no puede definirse debidamente como consistente en algo. Por ejemplo, la proposición de que la autosuficiencia es buena, es sintética. En resumen, al enumerar las características mencionadas, no hemos tratado de analizar el Bien. Esas características participan del Bien... El Bien se describe formalmente, aun en forma matemática; es una proporción. No es una cualidad que inmediatamente se deje sentir... La medida es el bien hasta donde la razón puede apreciarla. A fin de cuentas, el Bien es inefable... La idea del Bien predomina en la filosofía de Platón... Cada caso particular y cada forma... están situados en un medio general de ser, del que dependen y con el cual mantienen cierta relación. Así pues, cada entidad tiene trascendencia propia; todas las entidades, excepto el Bien. El Bien es una totalidad; por su naturaleza abarca, pero no excluye; y el no-ser, que se mezcla con todos los seres, no se mezcla con el bien. El Bien no tiene conexión con cosa alguna, más allá de sí mismo. A este respecto, la idea del Bien y la idea del Ser se hallan en contraste una con otra. De aquí que el Bien no sea un ser, sino algo más allá del ser, y la fuente del ser... Los valores son distintos de las cosas; el Bien es un principio de crítica para el reino de todo Ser, existencial y esencial." 8

Esta exposición del Bien, como lo concibe Platón, enumera todas las propiedades de la ciencia de los valores: estructura y consistencia, formalismo y aplicabilidad, carácter absoluto y relatividad, alejamiento de la existencia, y no obstante relación con ella. Veamos ahora si Platón desarrolla esta ciencia, y en tal caso, en qué forma, pormenorizadamente.

Como lo hemos visto, la cuestión está en saber qué es el Bien, si no es algo empírico, sino conocimiento. ¿Qué clase de conocimiento es? Hay tres respuestas a esta pregunta, la nominalista o lógica, la realista o metafísica, y la empírica o epistemológica (la científica, en el sentido que hoy damos a la

8 Raphael Demos, op. cit., págs. $5^{2}, 61,62,64,71$. 
palabra). Estas tres preguntas aparecen en la exposición que hace Platón acerca del conocimiento del bien. Forman las etapas de su obra al paso que ésta se desenvuelve a través de su vida creadora.

\section{Segunda etapa: La solución nominalista o lógica}

En el diálogo Cratilo o Sobre la Corrección de los Nombres, Platón discute un aspecto particular del conocimiento: la relación entre las cosas y sus nombres, o como diriamos hoy, la semántica del Valor. ¿Conocemos las cosas si conocemos sus nombres? ¿Qué es la significación de los nombres y cuál es la relación entre esa significación y la naturaleza de las cosas nombra. das? Platón discute tanto las cosas individuales y la relación con sus nombres propios, como las clases de cosas y la relación con sus nombres generales; pero se da énfasis a las cosas individuales y a los nombres propios.

La cuestión que se discute desde todos los puntos de vista es si la naturaleza de las cosas puede encontrarse o no en sus nombres. ¿Cuando se nombra correctamente a las cosas son entonces aquello por lo que se les da el nombre? Esta pregunta tiene importancia axiológica. Así como la lanzadera es un instrumento para separar el tejido, también es el nombre un instrumento para distinguir una cosa de otra, de acuerdo con las diferencias en su naturaleza. "El tejedor, entonces, usará la lanzadera bien -y 'bien' significa como un tejedor - y el maestro usará el nombre bien -y 'bien' significa como un maestro" (Cratilo, $388 \mathrm{C}$ ). El nombre adecuado caracterizará correctamente a la cosa nombrada, y la cosa, cuando ha sido caracterizada correctamente, corresponderá en su naturaleza a lo que el nombre dice. Entonces estará haciendo "bien" lo que el nombre dice que está haciendo. Esto significa que el nombre sirve como la norma de lo bueno.

Hay una gran distancia desde Cratilo hasta la teoría de las ideas -pero el Cratilo es el origen de la teoría de las ideas. Las ideas no son otra cosa que normas de valor; brotan de nombres generales, y los nombres generales, o conceptos, brotan de la clase de nombres que se discuten en Cratilo. El nombre no es un concepto, pero desempeña todas las funciones que desempeñan los conceptos. Cada nombre, por lo menos en su forma original, es una descripción de aquello que nombra. El nombre correcto es una descripción correcta; sus letras ocupan el lugar tomado por los atributos del concepto, y la etimología ocupa el lugar tomado por la lógica. ${ }^{9} \mathrm{El}$ nombre es correcto si la cosa corresponde a él y es lo que dice el nombre, o se encuentra en la

9 Consúltense las investigaciones de Ernst Cassirer sobre el desenvolvimiento de los conceptos de las formas onomatopéyicas y de los nombres propios, y la "dominación del flujo de cambio de Heráclito" por el idioma _cl mismo problema que el de Cratilo. The Philosophy of Symbolic Forms, vol. I, cap. II; cap. IV, secs. I y 11, New Haven, 1953, págs. 190 sig., 280 sig., 295 sig. 
clase nombrada. Sócrates usa la etimología de los nombres propios para determinar su significado, y compara el carácter del que lleva el nombre con los "caracteres" del nombre. Esto significa que convierte al nombre en la norma del valor de la cosa nombrada. ${ }^{10}$

Así, la solución nominalista del problema de lo bueno es: una cosa es buena si se la nombra correctamente. Para Platón esta solución fue un experimento, descartado inmediatmente. No se hizo de nuevo en la ética occidental. Sin embargo, en la ética oriental ha tenido una larga historia, en la filosofía de Confucio - que aunque no se desenvolvió sistemáticamente, tuvo en cambio efectividad social. "Cuando se le preguntó a Confucio cuál era el primer paso para gobernar a un país, contestó: Rectificar nombres (Jeng Ming). Que el gobernante sea un gobernante, el ministro un ministro, el padre un padre y el hijo un hijo. Porque cuando las cosas dejan de significar lo que sus nombres indican, entonces, dice Confucio, las gentes se confunden y no saben mover las manos y los pies." 11 "Rectificar por medio de la acción" es el carácter Jeng, que significa "gobernar" o "gobierno". "El arte de gobierno consiste simplemente en hacer las cosas bien o poner las cosas en sus lugares apropiados." 12 Esto es similar a la idea de Platón sobre la justicia. "Haciendo cada uno su trabajo adecuado." "13 "Si se conduce al pueblo con corrección, ¿quién osará no ser correcto?" 14 La noción confucianista de $L i$ da el concepto fundamental de orden, "el orden de las cosas". ${ }^{15}$ Un corolario de la doctrina de $L i$ es la importancia de la terminología: a todo debe llamársele por su propio nombre. ${ }^{16}$ Confucio dijo: "una taza de melón que ya no parece taza de melón y la gente sigue diciendo: '¡una taza de melón! . . juna taza de melón. .. !" " 17

Tanto la doctrina de Confucio como la de Platón sobre el uso correcto de los nombres contiene una guía para la ética científica. Porque ya que ambas usan el nombre de una cosa como la norma de su valor, y ya que los nombres son elementos de lógica, pueden estructurarse normas de valor en

10 Publicaciones sobre el significado y la significación de Cratilo: J. Derbolav, Platos "Kratylos", Saarbrücken, 1953; E. Haag, Platos Kratylos, Stuttgart, 1953. K. Büchner, Platons Kratylos und die moderne Sprachphilosophie, Berlin, 1936; V. Goldschmidt, Essai sur le Cratyle, Paris, 1940. También véase Raphael Demos, The Philosop'hy of Plato, New York, 1939, cap. xIv; W. Lutoslawski, The Origin and Growth of Plato's Logic, London, 1897, págs. 220 sigs.; A. E. Taylor, Plato: The Man and His Work, London, 1949, págs. 75 sigs. Sobre Cratilo como introducción a las teorías lógicas del Fedón y presuponiendo la conclusión de las cuestiones éticas resumidas en Gorgias, consúltese a Lutoslawski, op. cit., pág. 231.

11 Confucio, Analectas, libro xur. Cf. Rose Quong, Chinese Wit, Wisdom and Written Characters, New York, 1945.

12 Lin Yutang, The Wisdom of Confucius, New York, 1938, pág. 218.

13 La República, IV, 433 .

14 Alfred Doeblin, The Living Thought of Confucius, Philadelphia, 1940, pág. 108.

15 Liki, XXVIII.

16 Lin Yutang, The Wisdom of Confucius, pág. 17.

17 The Wisdom of China and India, Lin Yutang, ed., New York, 1942, pág. 826. 
términos de lógica. Este principio se usa hoy como la base de la axiología formal.

Platón pasó desde la solución nominalista del problema del valor a la solución realista, la relación entre las cosas y las ideas.

\section{Tercera etapa: La solución realista o metafisica}

La 'solución nominalista se ocupó primordialmente de los nombres propios. Si se usan nombres o conceptos generales, sólo pueden nombrarse correctamente clases de cosas, y ninguna cosa individual puede llenar nunca el concepto. Las cosas individuales corresponden a sus conceptos de clase solamente hasta cierto grado. De ahi que aparezca un vacío entre la cosa y su nombre; no es posible ninguna correspondencia entre los dos. Si ha de usarse el nombre general como la norma de valor, tendrá que ser un ideal al que nunca llegará ninguno de los ejemplos empíricos. Platón, de manera natural, pasó del uso axiológico del nombre propio al del nombre general. Consideraba el concepto lógico como un ideal axiológico, independiente del reino empírico y normativo del mismo - una doctrina sugerida ya en Cratilo- y asi llamó al concepto, trascendente y normativa, la Idea. En esta forma eliminó el concepto del reino de la lógica y lo colocó en el de la metafísica. Su reino de ideas es la hipostatización axiológica del concepto lógico y emana del hecho lógico de que ninguna cosa empírica puede llenar el concepto de su clase.

Naturalmente, este hecho pudo también haber llevado a Platón en la dirección opuesta: de vuelta a la cosa más bien que más allá del concepto. Pudo haber visto primordialmente la realidad en la cosa misma más bien que en su nombre - como a veces lo sugiere en Cratilo- y lo inadecuado del nombrar no en lo inadecuado de la cosa como un miembro de su clase o como un ejemplo del concepto, sino en uno del concepto. En este caso, pudo haber continuado la dirección nominalista investigada en Cratilo. Pero ya estando allí, abandonó esta dirección y declaró como su "conclusión" que las realidades ( $\tau \dot{\alpha}$ ö $\partial \tau \alpha)$ tienen que aprenderse y descubrirse "... no por los nombres sino... a través de ellas mismas" (Cratilo, 439 B). Y por "realidades" se refería ya en Cratilo no a las cosas ni a sus nombres sino a un tercer reino, que no está sujeto al flujo de la actualidad empírica, sino que es absoluto, inmutable, y así, el único capaz de suministrar conocimiento seguro -el reino más tarde llamado de las ideas. La transición de nombre general a idea es una vez más lógica, y preparada en Cratilo: es designar a un nombre general con un nombre propio. Éste es el proceso lógico de la hipostatación. Todo lo que se dijo en Cratilo sobre aplicar nombres a las cosas, ahora podía decirse sobre la aplicación de nombres a las ideas. Esto lo hizo Platón en La República: el legislador de Cratilo, que da nombres y los rela- 
ciona con las cosas, y el dialéctico, que guía al legislador es, en La República, el filósofo, quien crea ideas y las relaciona con el mundo de las cosas. $L a$ República es el diálogo sobre las ideas y sus expertos, así como Cratilo es el diálogo sobre los nombres y sus expertos.

Ya que Platón había llegado en el Protágoras a la conclusión de que el Bien es el conocimiento, ahora igualaba el inmutable reino de las ideas con el Bien, y depositaba a la Realidad, que no encontraba en las cosas ni en los conceptos, en ese reino metafísico. De aquí que ahora tengamos la solución realista del problema del Bien. Lo que es real es la idea; las cosas empíricas solamente la imitan y participan en ella. La norma de valor se convirtió en una reserva esotérica para aquellos que tenían una relación personal con los conceptos individualizados. Todos los esfuerzos de Platón por volver racionalmente accesible al reino de las ideas -aun a través del uso de las matemáticas - fracasaron. Platón no contaba con los instrumentos lógicos para crear una axiologia formal. Tenía que darse por satisfecho con el mito y la metáfora (República, VI, 508, VII, 514 sigs.). Por eso su teoría del valor tenía que permanecer estéril. Nuestra decepción con Platón es semejante a la decepción de Sócrates con Anaxágoras (Fedón 97 sig.) - había dẹsarrollado un principio pero no pudo aplicarlo.

Con el concepto de clase convertido en Idea, la relación entre la cosa y el nombre se hipostatizó en una relación entre la cosa y su prototipo trascendente, la noción de la "participación". El Valor, la clase de conocimiento que en Cratilo aparecía todavía en la relación entre la cosa y el nombre, queda ahora eliminado del reino tanto de las cosas como de los nombres, y por lo tanto, del reino de la comunicación misma. La participación excluye la comunicación. Las únicas cosas que pueden ser comunicadas son "productos" del bien, contrapartes místicas del mismo; su "interés", pero no el capital.

Así, Platón vio y desarrolló un aspecto —el más fundamental- de la axiologia formal, su carácter remoto del reino empírico. Estableció "la distinción... entre la multiplicidad de las cosas que llamamos buenas o bellas o como quiera que sean, por una parte, y la Bondad misma o la Belleza misma y así sucesivamente" (Repuiblica, VI, 507 B. Cf. Fedón 100). Pero nunca hizo ver la conexión lógica entre el reino del valor y el de las cosas, ni la estructura lógica del reino del valor mismo. A este tema siempre lo "archiva", y "retrocede casi al llegar al objetivo" (República VI, $506 \mathrm{D}, \mathrm{E}$ ) -como lo sugiere Shorey, no por "misticismo supersticioso, sino como una negativa deliberada para reducir a una fórmula aquello que requiere ya sea un volumen o un símbolo". ${ }^{18}$ Sea lo que fuese aquello que Platón haya conocido acerca de lo bueno, lo que nos ha dado es el principio del formalismo, pero en términos místicos. Lo Bueno es tan formal como el número; pero Platón

18 The Republic, Loeb Classical Library, pág. 95, nota f. Sobre la significación de Fedón en relación con Cratilo véase Lutoslawski, op. cit., págs. 245 sigs. 
concibe al número mismo de acuerdo con el. sentido de Pitágoras, y por eso resulta místico.

La hipostatización de los conceptos en ideas se desarrolla en Fedón hasta constituir un sistema, cuyos principios son los de las matemáticas (Fedón 97 sig., cf. A. E. Taylor, op. cit., págs. 201 sig.), pero cuyos detalles no son ni discernibles ni comunicables. El vacío entre el nombre y la cosa se ha ensanchado ahora hasta ser un abismo entre el reino de las ideas y el reino de la experiencia de los sentidos. Este vacío se hace ver mediante ejemplos matemáticos, v. gr., la noción de igualdad. La igualdad no se encuentra en las cosas sino que es puramente un resultado del pensamiento. La idea de la igualdad es demasiado perfecta para poder encontrar realización en el mundo físico. Una vez comprendida y recordada, se sabe que la igualdad absoluta es radicalmente diferente de cualquier igualdad observada. Este principio se extiende a otras ideas, no sólo de relación matemática sino también de justicia, santidad, y de todo lo predicado acerca de particularidades. Todas estas ideas tienen una existencia eterna y necesitamos haberlas conocido antes de que comenzáramos a ver, a oír y a recibir otras impresiones de los sentidos (Fedón 75$)^{19}$

En Fedón, go, leemos por primera vez acerca de una ciencia del pensamiento, o lógica. La razón humana tiene la facultad de un conocimiento infalible. Nuestros errores se deben no a la debilidad de nuestra razón, sino a la influencia de los sentidos (Fedón $6_{5}$ D-66 A). ${ }^{20}$ Es el alma lo que está dentro de nosotros, y que nos da esta clase de conocimiento. Es a lá vez epistemológico y ético, es el conocimiento del valor. Nos proporciona penetración tanto de la Verdad como del Bien. El Banquete nos había dado una penetración similar de la Belleza. Así, la teoría de Fedón es una generalización de la experiencia estética del Banquete. ${ }^{21}$

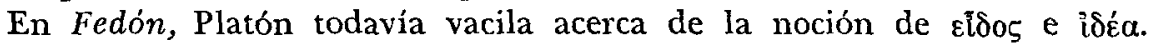
Esta vacilación produce una variedad de términos para la peculiar relación entre la idea y los particulares. ${ }^{22}$ Sobre la hipótesis de las ideas puede construirse un sistema de ciencia consistente, mediante la generalización progresiva hasta el principio más elevado (Fedón, 101 D)..23 Lógicamente, la doctrina culmina en la ley de la contradicción (Fedón, $102 \mathrm{E}$ ).

Fedón resuelve el problema planteado en Cratilo y decidido en contra del heraclitismo. Platón postula no sólo la estabilidad de las nociones, ya reconocida en Cratilo, sino también su independencia de la inteligencia humana. Así —otro ejemplo matemático_ la adición es sólo el aspecto subjetivo

\footnotetext{
19 Véase Lutoslawski, op. cit., pág. 249.

20 Taylor, op. cit., págs. 180 sigs.

21 Lutoslawski, op. cit., págs. $254,24^{6}$.

22 Lutoslawski, op. cit., pág. 255.

23 Lutoslawski, op. cit., pág. 256 .
} 
de la relación eterna que subsiste independientemente de nuestra razón entre la unidad y la idea de dos (Fedón, 97 A).24 "El Fedón lleva el idealismo de Platón hasta su punto más elevado y contiene una representación consciente de todas las consecuencias que se derivan de la hipótesis fundamental buscada en el Cratilo, percibida en el Banquete, y demostrada aquí." 25

En los tres diálogos bien definidos Cratilo, El Banquete y Fedón, la cuestión ética, tan discutida en los diálogos socráticos, se convierte en secundaria y el problema lógico del conocimiento se vuelve primordial. ${ }^{26}$ El grupo sirve de introducción a la República, y a Fedro.

Con la solución metafísica lo bueno ha retrocedido a un reino que se basta a sí mismo, infinitamente remoto (trascendente) e incomunicable. Las cosas en comparación con ello son, a su vez, infinitamente remotas del reino del valor. La solución realista fue así más bien una disolución, una completa ruptura entre los dos mundos: lo bueno no podía confirmarse ya con las cosas. Esto hizo necesaria la cuarta etapa.

\section{Cuarta etapa: La solución empirica o epistemológica}

a) Transición de la tercera etapa a la cuarta. La transición de la tercera etapa a la cuarta constituye un acercamiento gradual entre los dos mundos del hecho y del valor, hasta que en la cuarta etapa misma se ponen en contacto y forman una nueva unidad compleja.

En La Repuiblica Platón va mucho más allá de los comienzos del Fedón; el mundo de las ideas se vuelve más definido y, hasta cierto grado, estructurado (República, $5_{24}$ sigs.). El papel prototípico del conocimiento matemático aparece en nuevos ejemplos matemáticos: la identidad sólo puede comprenderse por la acción del pensamiento (República, 526 A): debemos a la claridad de los números el poder distinguir las cosas que ante nuestros sentidos aparecen confusas $(524 \mathrm{C})$; la diferencia entre la exactitud numérica y la exactitud de la percepción de los sentidos es el origen de la investigación racional acerca de la naturaleza de la cantidad $(524 \mathrm{C}):{ }^{27}$ existe una diferencia similar entre los modelos materiales de las figuras geométricas y las figuras ideales que representan. El filósofo avanzará más allá de la aplicación práctica e inmediata, al conocimiento teórico de lo matemático, para

24 Lutoslawski, op. cit., pág. 258. Cf. la comparación moderna entre la definición de número y de valor, Robert S. Hartman, La Estrustura del Valor, México, 1959, págs. 85 sigs.

25 Cf. Lutoslawski, op. cit., pág. 259 .

26 Cf. Lutoslawski, op cit., pág. $26_{5}$.

27 Cf. Lutoslawski, op. cit, pág. 299. En lo siguiente se dan, al lado de las referencias a Platón, las correspondientes referencias a Lutoslawski. Aunque Lutoslawski no describe el desarrollo de Platón de la manera expuesta en este ensayo, su obra parece ser una prueba implícita del planteamiento aquí dado. 
comprender la naturaleza de la cantidad misma sin preocuparse de las ventajas prácticas $(525 \mathrm{~B}, \mathrm{C})$. Esos estudios teóricos desarrollan un órgano del alma más valioso que mil ojos, porque es el único ojo que contempla la verdad $(527 \mathrm{D}, \mathrm{E}){ }^{28}$ Penetra hasta los principios absolutos de todo conocimiento y hace así posible la verdadera ciencia; porque la verdadera ciencia no puede basarse en primeros principios desconocidos e incognoscibles $(533 \mathrm{C})$. La ciencia de la ciencia es la Dialéctica que se eleva por encima de todos los comienzos hipotéticos hasta el principio absoluto. Esta cima se alcanza mediante la visión de la idea más elevada, a la que se llega por el estudio incesante, por la capacidad de "hacer preguntas y contestarlas" (531 E, 534 D. Cf. Cratilo 990 C); y el arte del análisis y de la síntesis de los conceptos (Fedro 266 B; Sofista 253 C, D).29

Platón concibió así un sistema general de conocimiento humano que incluía a todas las ciencias y las unía en un conjunto (República $537 \mathrm{C}$ ); todos los detalles de la existencia, según creía, podían ser puestos en relación con un principio definitivo. Este concepto de la conexión entre la idea más elevada y los detalles más nimios de la experiencia de los sentidos se ha visto en gran manera confirmado por la historia de la ciencia. ${ }^{30}$ El principio más elevado para Platón, era un modelo contenido en el alma $\left(48_{4} \mathrm{C}\right.$ ). Platón exigió para él tanto la mayor exactitud como la más alta generalización $(504 \mathrm{D}, \mathrm{E}){ }^{31}$ Este requisito se ha satisfecho para la ciencia natural en las matemáticas; para la ciencia moral tendrá que serlo en la axiología.

Platón mismo trató de estructurar tanto el reino natural como el moral, empleando las matemáticas; el primero en el Timeo y el último en Filebo. Pero más acertadamente fue su estructuración del reino moral por medio del mito, como el mito del Sol y el de la Cueva, que exponen "con todos sus detalles" lo que tiene que decir. ${ }^{32}$ De esta manera, si bien Platón no pudo desarrollar la dialéctica, previó su papel: formular preguntas acerca de la realidad natural y moral, y contestarlas por medio de sistemas, como las matemáticas. La dialéctica, podemos decir, es la ciencia de los marcos de referencia para las ciencias. Es la ciencia de la ciencia, la ciencia de aquello que es "digno de pensarse", es decir, de "axiomas", del principio más elevado del valor aplicable a todo pensamiento. Abajo de la dialéctica, en el segundo nivel más alto del conocimiento, están el pensamiento matemático y otros pensamientos sistemáticos, emanados del principio de la dialéctica $(534 \mathrm{~A})$. Tanto la dialéctica como el pensamiento sistemático (Diánoia) reciben el nombre de Noesis, y están en oposición a la facultad inferior de opinión Doxa

28 Cf. Lutoslawski, op. cit., pảgs. goo sig.

29 Lutoslawski, op. cit, págs. 332, 406, 421.

30 Véase Ernst Cassirer, Substance and Function, Chicago, 1923, cap. I.

31 Lustoslawski, op. cit., pág. 303.

32 Lutoslawski, op. cit., pág. 304. 
(534 A), que a su vez se subdivide en Pistis, Creencia, con referencia a las cosas; y Eikasia, Conjetura ("semejanza"), con referencia a las imágenes ( 5 1 I E). Lo que es susceptible de opiniones es todo aquello que podría ser diferente de lo que es (479 A), una definición basada en la ley de la contradicción expuesta en Fedón ( $103 \mathrm{~B}$ ), según la cual se encuentran contradicciones aparentes en las cosas pero no en las ideas. Solamente las ideas son objetos propios de la ciencia. El pensamiento es independiente del accidente empírico (República 454 B, 455 A). ${ }^{33}$ Hasta las mujeres pueden pensar, y pensar tan bien como los hombres.

Durante la primera parte de su actividad literaria, en el Banquete y Fedón, Platón creyó en la existencia objetiva de ideas fuera de particulares y fuera del alma individual. "Durante el periodo medio del Platonismo, hasta donde puede conjeturarse por los indicios que se dan en La República y en Fedro, se ha mantenido la misma convicción con una definición más clara de la relación entre las cosas y las ideas, como consistiendo en su similaridad, pero se ha subrayado con menor énfasis la independencia [de las ideas], y... toda la parte mítica del Fedro puede muy bien estar de acuerdo con una concepción de ideas en el sentido que tuvieron para Kant." 34

Una vez que Platón hubo reconocido la existencia de las ideas, se consagró a su orden y jerarquía, más allá del orden de las ideas morales, que parecían no dar suficiente amplitud para la tendencia dialéctica de distinguir y clasificar. ${ }^{35} \mathrm{El}$ resultado fueron los diálogos Teeteto y Parménides. Éstos también son diálogos lógicos, y es muy posible que Platón estuviera tratando de afilar el instrumento con el cual atacar de nuevo a la ética. Muchos de los problemas de Cratilo están ahora profundizados. ${ }^{36}$

Las categorias de la razón ocupan el lugar de la existencia por sí misma (Teeteto 155); la metafísica es sustituida por la epistemologia, ${ }^{37}$ un desarrollo que puede decirse plantea al conocimiento a la mitad de la distancia entre el nominalismo y el realismo, presuponiendo una relación definida entre el objeto y el sujeto del conocimiento.

En Teeteto (185 sig.) Platón da una especie de cuadro de las categorias, ${ }^{38}$ nociones generales conocidas por el alma a causa de su propia actividad: Existencia, Diferencia e Identidad, Unidad y Pluralidad, Similaridad y Disimilaridad. ${ }^{39}$ Estas categorías tienen una estrecha relación con los particulares observados por los sentidos. Así cambia Platón la actitud hacia los fenómenos físicos en Fedón y La República; muestra una actitud más científica -en

33 Lutoslawski, op. cit., pág. 307.

34 Cf. Lutoslawski, op. cit., pág. $3^{61}$.

35 Cf. Lutoslawski, op. cit., pág. 370.

36 Cf. Lutoslawski, op. cit., pág. $3^{82 .}$

37 Sir David Ross, Plato's Theory of Ideas, London, 1951, pág. 103.

38 Lutoslawski, op. cit., págs. 373 sig.

39 Parménides, 130 B; Sofista, 254 sig. Véase Lutoslawski, op. cit., págs. $4^{\circ} 7$ y 428 . 
el sentido moderno de la palabra- y anticipa descubrimientos científicos modernos tales como el del calor como una forma de movimiento. El conocimiento ya no es una simple intuición de las ideas preexistentes, ni es simplemente una relación entre la cosa y el nombre, sino un producto de la actividad de la mente. ${ }^{40} \mathrm{El}$ aparato humano de cognición es reconocido como tal. La contradicción es una posibilidad epistemológica, aunque no una posibilidad lógica. Lo bello y lo bueno se ven apareados con sus opuestos, como lo son otras categorías del pensamiento (Teeteto $186 \mathrm{~A}$ ), y no simplemente asociados como en La República y Fedro. De nuevo se subraya la necesidad de definición como en los primeros diálogos, pero ahora se hace en forma más sistemática. Logos (explicación racional) se divide en tres tipos: expresión, enumeración de partes y definición (Teeteto 206 D-208 E. Cf. Sofista $253 \mathrm{E}, 232 \mathrm{~A}, 240$ ). ${ }^{41} \mathrm{La}$ definición es la indicación de la diferencia específica que distingue a un objeto determinado de todos los demás. El conocimiento mismo es un objeto de conocimiento, y requiere una definición (Teeteto $200 \mathrm{D}){ }^{42}$ y sin una definición del conocimiento es imposible una definición del error (ibid). Teeteto no da esta definición del conocimiento, pero sí la da Parménides: el conocimiento es un sistema de nociones, desde la más alta hasta la más baja, que entran en múltiples relaciones mutuas, de acuerdo con la ingeniosidad del pensador (Parménides $135 \mathrm{D}, \mathrm{E}$ ). ${ }^{43}$ De esta manera el reino de las ideas ha asumido dinámica mediante su referencia a la inteligencia humana.

El bien también es no solamente una clase de conocimiento, sino a la vez un objeto de conocimiento y esto requiere definición. Platón no usa en el Filebo las categorías desarrolladas en Teeteto; pero en la axiología moderna las tres clases de explicaciones que allí se disputan - y la definición del conocimiento que se da en Parménides - son de importancia fundamental para la definición del bien.

Como a la etapa socrática siguió la exposición ética positiva —en La República-, así también a la segunda etapa crítica la siguió la enseñanza positiva lógica, metafísica y ética. ${ }^{44} \mathrm{La}$ enseñanza ética de este último periodo se da en Filebo y estuvo precedida por el Sofista y el Político. "En Jos diálogos Socráticos [las ideas] son primariamente conceptos lógicos; en el Parménides y el Sofista son esencias metafísicas, que en el Filebo se convierten en categorias lógicas primariamente, que constituyen al mismo tiempo la estructura de la realidad; en el Fedro y el Banquete son objetos estéticos y objetivos morales e ideales." $4 \tilde{\jmath}$

40 Lutoslawski, op. cit., pág. 375 .

41 Véase Lutoslawski, op. cit., pág. $4^{22 .}$

42 Lutoslawski, op. cit., pág. 384 .

$\$ 3$ Lutoslawski, op. cit., págs. $4^{06}$ sig.

44 Lutoslawski, op. cit., pág. 416.

45 I. Edman, The Philosophy of Plato, Neẉ York, Modern Library, pág. xxxvii. 
En el Sofista la dialéctica ya no es, como en La República, el conocimiento del Bien, sino que como en el Fedro, es la ciencia de la división de las nociones (Sofista 253 C, D). ${ }^{46}$ En el Sofista aparece por primera vez un método lógico esencialmente diferente en su forma y contenido del método dialéctico de La Repriblica ( 533 C). Allí la dialéctica no significaba más que la visión de la idea del Bien. El nuevo método lógico es el de la clasificación.47

El método de la aplicación correcta de nombres, que se discutió en Cratilo, se eleva así a una nueva dimensión. 48 El filosofo encuentra las verdaderas similaridades y diferencias de las cosas, que permiten dar definiciones exactas de cada tipo de ente como perteneciente a una clase general. Después de la conversión etimológica de los nombres propios en seudoconceptos y la conversión metafísica de los conceptos en nombres propios, como ideas, Platón finalmente descubrió el terreno medio y consideró los conceptos como lo que son -es decir, nombres de clase. Da la prescripción para la clasificación: Debe cuidarse de no mezclar las cosas que no son de la misma clase (Sofista $235 \mathrm{C}, 231$ ); muchas nociones sobre las cuales quienes disputan parecen estar de acuerdo, se encuentran insuficientemente definidas ( $24{ }^{2} \mathrm{C}$ ); existe una diferencia entre la enumeración de ejemplos y la definición de la clase a la que pertenecen los ejemplos (240 A).49

Todas estas distinciones desempeñan un papel fundamental en la estructura de la axiología formal.

La dialéctica, que en un principio significaba solamente el arte de formular y contestar preguntas, que pasó a ser luego el conocimiento de las ideas, se convierte ahora en la ciencia de la comprensión de las ideas en movimiento: siguiendo cada idea a través de la multiplicidad de sus apariencias, distinguiendo dentro de cada noción muchas diferencias y uniendo de nuevo una noción con muchas otras dentro de una clase más elevada (Sofista $253 \mathrm{D}$ ). Las ideas aquí mencionadas evidentemente sólo pueden ser nociones de la mente humana, y nunca ideas con existencia propia de un reino "por encima del cielo".

De esa manera las ideas, que en un principio pasaron de la inmanencia a la trascendencia, y que luego se convirtieron en prototipos de cosas, se han vuelto ahora nociones dinámicas inherentes en el alma. Se reconoce al Movimiento como parte del verdadero Ser. La posición de Heráclito, que tan laboriosamente se dejó atrás en el Cratilo, vuelve a ser abordada.50

En el Politico el principal instrumento de la preparación filosófica vuelve a ser de nuevo la facultad de formular y contestar preguntas (286 A).51 Cada

\footnotetext{
46 Cf. Lutoslawski, op. cit., pág. 421 .

47 Véase Lutoslawski, op. cit., pág. 419.

48 Lutoslawski, ibid.

49 Lutoslawski, op. cit., pág, 422 .

50 Lutoslawski, op. cit., pág. 425.

51 Lutoslawski, op. cit., pág. 444 .
} 
ciencia está construida por medio de la hábil selección de elementos apropiados, y de la unión aceptada de particulares semejantes, en una sola totalidad. Para esto se necesita una definición exacta de cada noción basada en el razonamiento y no en la percepción de los sentidos. ${ }^{52}$ Pero tal definición exacta no puede aplicarse a la ética. De esta manera Platón niega la posibilidad de prueba en las cuestiones morales, que afirma un empírico como Locke, en un trueque peculiar de los papeles, que es típico para el caos en el razonamiento ético - y para el de la acción, como lo pone en claro Lutoslawski cuando se refiere a la Inquisición en conexión con ciertas enseñanzas de Político.53

Aquí aparecen por primera vez dos nociones fundamentales de axiología, la división del conocimiento en puro y aplicado $\left(25^{8} \mathrm{E}\right)$ y una norma de valor, adecuada al nuevo giro práctico de la discusión, el medio (283 E sigs.) -nociones que se desenvuelven ambas en Filebo (57 A-E; $25 \mathrm{D}, \mathrm{E}, 26)$ y se desarrollan en la Ética de Aristóteles. Las ideas pierden ahora por completo su condición metafísica y se convierten en nociones universales de la mente humana -o de cualquiera otra más elevada. "La existencia separada de las ideas fuera de cualquiera mente es un absurdo poético que podía subsistir sólo durante un tiempo muy limitado en la imaginación de un pensador como Platón." 54

En el Politico todavía más que en el Sofista, Platón se preocupa por el método. La culminación de este desenvolvimiento aparece en Filebo.

b) La cuarta etapa. En Filebo, Platón vuelve finalmente a la ética. El subtítulo es "Sobre el Placer-Ético". Aquí es completa la unión del conocimiento práctico con el especulativo. La razón reina tanto en la tierra como en el cielo $\left(28 \mathrm{C}, 3^{\circ} \mathrm{D}\right)$ y todo el magnífico universo da testimonio de ello (28 B). La ciencia se vuelve coextensiva con toda la creación, la verdadera sabiduria consiste en definir las ideas y sus relaciones, hasta que obtengamos un sistema continuo de nociones desde la "una" más elevada hasta "muchas", a través de graduaciones medidas, subdividiendo cada idea en el número más pequeño, a fin de dar la especificación detallada de cada subdivisión de la una ( $16 \mathrm{D}$ ). Este sistema de ideas se encuentra en la naturaleza, pues todo ha sido arreglado por la razón, y nuestras ideas son copias de la finalidad del mundo, que existen en la mente de quienes las crean. "Ya no queda ni huella de una existencia de ideas separadas de las almas y de las cosas particulares. Cada idea es el resultado de la impresión que la unidad natural de un grupo de particulares produce en un alma observadora." 55 Debe tenerse cuidado de no pasarse ni con demasiada rapidez ni con demasiada lentitud de uno a la infinidad de particulares, a causa de la ignorancia de términos me-

62 Lutoslawski, ibid.

53 Lutoslawski, op. cit., págs. 444 sig.

54 Lutoslawski, op. cit., pág. 447.

55 Lutoslawski, op. cit., págs. 463 sig. 
dios convenientes (17 A). ${ }^{58}$ Aquí aparece por primera vez la noción del término medio, en su significado técnico de "término medio" entre el concepto y el caso o ejemplo, como más tarde lo usó Aristóteles en su teoría del silogismo; pero aquí con una significación profunda - ya que quiere decir "términos medios" entre uno y la infinidad - significación que no ha sido desarrollada en la lógica, pero que ha tenido desarrollo en la axiología formal. ${ }^{57}$

La más alta perfección, como en La República, se les atribuye a la dialéctica y a las matemáticas. Solamente los objetos dialécticos o las ideas eternas conducen a la certidumbre absoluta. Pero estas ideas, que ya no están separadas o que existen por sí solas, como estuvieron en los diálogos anteriores, tienen ahora una "eternidad" muy diferente de la metafísica; simplemente Ia de la lógica, de validez formal. Las ideas son entidades lógicas. ${ }^{58} \mathrm{La}$ "certidumbre absoluta" a la que conducen es, entonces, no la metafísica y por tanto la certidumbre intuitiva, sino la certidumbre lógica. Ya no es más la certidumbre esotérica de los intelectualmente elegidos. Es la certidumbre que se obtiene por medio de la explicación racional. Este método racional está ahora reservado para la ciencia natural; en Filebo se aplica a la ciencia moral.

En Filebo, se representa a la ciencia natural como deficiente en exactitud porque no se refiere a ideas eternas sino a apariencias cambiantes. "Era la convicción permanente de Platón la de que la inmensa variedad del mundo físico no admitía un conocimiento perfecto ${ }^{59}$ - un prejuicio que debía prevalecer por cerca de dos mil años y que casi destruyó a Galileo. "La idea de la unidad en la variedad persigue aquí a la mente de Platón, al igual que en todos los diálogos dialécticos." ${ }^{0}$

El método de Platón para enfrentarse con esto fue el de la división y clasificación, que es el principal tema de los tres diálogos posteriores a Parménides. Al dar una escala desde lo infinito a lo finito, estas operaciones lógicas hacen posible una ciencia general del mundo. Se aplican a "nociones de la mente humana, que son semejantes a las ideas divinas. Las ideas... existen en la mente divina, de donde pasan a nuestras almas a través de la observación de particulares concretos. El mundo material está construido de acuerdo con las ideas de Dios, y necesitamos encontrarlas por medio de comparaciones y de distinciones de particulares". Esta es la convicción que

56 Lutoslawski, op. cit., pág. $4^{6} 4$.

57 En las estructuras axiomáticas. Véase Robert S. Hartman, "The Logic of Value", Review of Metaphysics, vol. XIV, No 3 (marzo 1961) y La estructura del valor, México, 1959, págs. 289 sigs. En la interpretación de A. E. Taylor, Plato: Philebus and Epinomis, Edinburgh, 1956, pág. 39 , la mezcla del finito y del infinito significa, en términos modernos, la aplicación de una variable a la infinitud de sus valores, es decir, cl procedimiento de la ciencia moderna.

58 Véase Edman, op. cit., pág. xxxviii.

59 Lutoslawski, op. cit., pág. 466.

60 Ibid. 
motivó a un hombre como Kepler. Aunque hay dos clases de existencias, la del mundo externo y la del eterno, de ideas y de almas - y Platón fue el primero en reconocer esta doble significación de la existencia-, la nueva dialéctica proporciona los eslabones entre los dos mundos. "Se distingue del Platonismo medio y de la anterior teoría de ideas por la mayor importancia que se concede a los particulares. Ninguna explicación del universo se acepta como suficiente, a menos que explique hasta el más pequeño y más insignificante detalle, así como la idea más grande." 61 Éste es el espíritu y el método típico de la ciencia moderna. "La unidad de toda la existencia no es ya una unidad abstracta, sino una cima construida sobre la base más amplia, sobre la experiencia universal de la humanidad."

Veamos ahora cómo se aplican este espíritu y este método al problema del Bien. La pregunta del Filebo es: ¿Qué es el Bien? Pero con "el Bien”, en este diálogo, no se significa solamente el bien formal de las ideas, sino también el bien empírico de la vida humana y, de hecho, la combinación de ambos. Platón distingue entre "el bien en sí mismo" y "lo bueno para el hombre" o "la buena vida" —entre el valor axiológico y el valor empírico, específicamente el valor moral. Así, a distinción de la mayoría de los investigadores de ahora, él no comete la falacia que G. E. Moore llamara la naturalista. Lo bueno es "una condición y disposición del alma que puede hacer feliz la vida para todos los seres humanos" (Filebo 11 D). El bien moral, en otras palabras, es la felicidad; y la cuestión estriba en saber si esta condición se alcanza por medio del placer o por medio de la sabiduría. El problema del Bien se ha bajado así al reino empírico, exactamente de acuerdo con los términos que más tarde. desarrollará Aristóteles.

El bien en sí es "alguna tercera cosa diferente y mejor que ambos" el placer y la sabiduria (Filebo $20 \mathrm{C}$ ) -es el objetivo perfecto y autosuficiente de todo deseo racional (20 D), y por el cual se genera todo (54 C). Éste es el bien axiológico. Solamente de él puede decirse con verdad que es bueno; es decir, una proposición con el predicado de "bueno" es analítica. De esta manera, "el Bien es bueno" es analítico; pero "el Placer es bueno" y "el Conocimiento es bueno" son sintéticos (Filebo 13 A, 14 A). ${ }^{63}$ Porque no todos los placeres son buenos ni todas las ciencias son buenas: algunos lo son y algunos no lo son. Del Bien, sin embargo, todos los casos son buenos. Así pues, la cuestión acerca de la bondad del placer y de la sabiduría, consiste en saber si en la ilimitada infinidad de placeres y de conocimientos pueden distinguirse tipos limitados, y entre ellos aquellos que son buenos. $\mathrm{Ni}$ el placer por sí solo ni la sabiduría por sí sola pueden ser el Bien, porque no se bastan a sí mismos; a ambos se les desea para una vida buena. Es

01 Lutoslawski, op. cit., págs. 470 sig.

62 Ibid.

03 A. E. Taylor, op. cit., pág. $4^{11}$. 
decir, no una vida que aspire únicamente al placer ni una vida que perșiga únicamente la sabiduría, sino solamente una vida que trate de alcanzar a los dos reunidos es una vida buena (22 B) - y una vida buena desea tanto la perfección como la autosuficiencia, que son la verdadera bondad. En otras palabras, una vida buena tiene que ser un ejemplo de bondad-y no de placer o de conocimiento. La vida buena es entonces de "las tres vidas propuestas" (22 B) la única que mezcla el placer con la sabiduría.

La cuestión entonces consiste en saber cuál es el carácter preciso de esta mezcla. Esto lleva al carácter formal del concepto "mezcla", como una relación entre lo ilimitado y lo limitado. Esta medida matemática (la fuente del término medio de Aristóteles) se aplica a los constitutivos empíricos del placer y la sabiduría, con el resultado de que lo bueno es una combinación de cinco ingredientes: (a) medida matemática, como "la naturaleza eterna", (b) la simétrica, perfecta o suficiente, $(c)$, sabiduria, $(d)$ ciencias, artes, opiniones verdaderas, $(e)$ placeres puros. Como se ve, $(b)$ es lo que se llama "el Bien", la "tercera clase" de bien que se encuentra por encima, tanto de la mente como del placer. Ahora aparece no como el más elevado elemento constitutivo de la bondad sino como el segundo en elevación; la fase más elevada está ocupada por "la medida, lo medido, lo que está ajustado o en su lugar".

Esto puede interpretarse en términos modernos, como "un fenómeno explicado dentro de su marco de referencia apropiado". El bien como autosuficiente y perfecto, es entonces la forma supra-empírica que es simétrica o estructurada. En otras palabras, el bien axiológico tiene que ser un sistema, y como tal "una forma de lo bello" (Filebo $6_{4} \mathrm{C}, \mathrm{E}$ ). Por encima del bien está la forma o pauta dentro de la cual debe estar comprendido el bien.

Entonces, este bien $(a)$ y $(b)$, que es uno, es decir, la pauta del bien, se aplica a la multiplicidad de los bienes empíricos. Éstos, en términos de dicha pauta, se ordenan en jerarquía -éste sería un tipo de axiología aplicada o de ética- con la sabiduría primero (c), después con las ciencias y las artes $(d)$, y finalmente con los placeres puros $(e)$-es decir, los placeres que no causan pena, tanto a la mente como a los sentidos.

Así, Filebo delinea nada menos que una completa ciencia del valor, tanto formal como aplicado. ${ }^{64}$

\section{Resumen y perspectiva}

Un sumario de las opiniones de Platón se encuentra en su última obra, Las Leyes, para expresar su última voluntad, y en la que nombra como

64 Consúltese a Lutoslawski, op. cit., págs. $4^{64}$ sigs. También A. E. Taylor, op. cit., cap. xvi; John Gould, The development of Plato's Ethics, London, 1955, cap. xvi; Nicolás Isidore Boussoulas, L'être et la composition des mixtes dans le "Philèbe" de Platon, Paris, 1952; A. E. Taylor, Plato: Philebus and Epinomis, Edinburgh, 1956. 
albacea de su herencia a una organización llamada el Consejo Nocturno. "Es - dice Gould - tal vez la conclusión más excitante de cualquiera de las obras de Platón" es y es realmente la conclusión de todas las obras de Platón. "El largo trabajo termina abruptamente, dándonos la impresión de una catapulta preparada y lista para lanzarnos todavía más lejos al corazón mismo del problema ético: ... Porque, al final de las Leyes, lo que se contempla como la misión del Consejo Nocturno es nada menos que un análisis de las

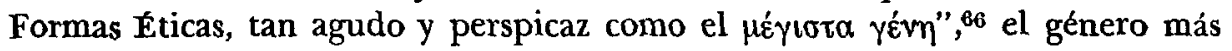
alto, las categorias en el Sofista (254 B sigs.).

Platón, en sus instrucciones al Consejo Nocturno, combina la percepción matemática y la moral en el Bien. El problema que plantea a sus albaceas consiste en encontrar cómo las cuatro virtudes, o sea la justicia, la templanza, la prudencia y el valor o coraje, pueden ser una y cómo también esa una puede ser cuatro. "La organización de toda la división ética de las Formas tiene que ser revisada. De esta manera, el Consejo Nocturno puede llegar a su posición, la visión de la verdad ética y la consiguiente capacidad para distinguir 'aquellas cosas en este mundo de cambios que son intrínsecamente buenas y aquellas que son malas'." 7

Pero el Consejo Nocturno tiene que investigar no sólo la relación entre las matemáticas y el valor, sino también entre las cosas y sus nombres, retrocediendo así al comienzo mismo de la investigación de Platón en el Cratilo. Después de que el Consejo haya investigado "de qué manera las cuatro son una y... de qué manera son cuatro" 88 procederá a investigar si, en el caso de las cosas que tienen un nombre y también una definición, el conocimiento verdadero consiste en conocer sólo el nombre y no la definición. "¿Puede el que es bueno para algo ignorar todo esto sin desacreditar aquello que se refiere a las verdades grandes y gloriosas?" pregunta el Ateniense, y Cleinias responde, "Supongo que no". ${ }^{69}$

Y ésta es la más elevada sabiduría a la que puede aspirar el Consejo. Todas las cuestiones posibles han quedado reducidas finalmente a dos especies: preguntar el nombre de un sujeto del cual se da la definición, o preguntar la definición de un nombre dado. ${ }^{70}$ Solamente lo último es conocimiento, de manera que el verdadero conocimiento es el conocimiento de la definición del nombre. Esto se aplica - y primariamente- al nombre "Bien" o valor.

65 Gould, op. cit., pág. 128.

G6 Ibid.

67 Ibid. Véase Leyes, $966 \mathrm{~B}$.

68 Leyes, 964 A. Consúltese $9^{6} 7 \mathrm{E}$, donde se pide a los miembros del Consejo que se compenetren con las leyes que regulan a las estrellas, a la astronomía y a las matemáticas para relacionarlas con la teoria musical, y para "aplicar ésta armoniosamente a las instituciones y a las reglas de la ética".

69 Ibid.

70 Leyes, 895 D; también véase Sofista, 218 C, y Epistola VII, 342 sigs. 
El Consejo necesita encontrar cuál es "ese principio que es el mismo en todas las cuatro" 71 y necesita "poder interpretar con palabras cuál es la verdad acerca de todas las cosas buenas". ${ }^{72}$ Tiene que definir, en otras palabras, lo que todas las cosas buenas tienen en común, la Bondad misma. Sus miembros deben ser filósofos del valor en el sentido de que necesiten conocer la relación entre lo uno y los muchos, y que necesiten tener "el conocimiento de clases que determina dónde las formas pueden tener comunión entre sí y dónde no". ${ }^{73}$ Necesitan ser maestros en el arte de la dialéctica, filósofos puros y auténticos. ${ }^{74}$

Solamente entonces estarán capacitados para realizar el bien en la acción. Para descubrir la naturaleza exacta del bien y realizar así la "gigantesca empresa" - como la llama Glaucón en La República ${ }^{75}$ - de investigar la naturaleza del valor, creándose una organización investigadora. Su programa no puede establecerse de antemano, pero tendrá que confiársele al Consejo una vez que se haya constituido. "En primer lugar, tendrá que formarse una lista de quienes por su edad, sus estudios, sus disposiciones y costumbres estén bien capacitados para cumplir los deberes de un guardián. En segundo lugar, no será para ellos fácil descubrir por sí mismos lo que tienen que aprender, o convertirse en el discípulo de uno que haya hecho ya el descubrimiento. Además, será vano escribir los periodos en los cuales tengan que recibir las diversas clases de instrucción; porque quienes aprenden no saben lo que se aprende con ventaja sino hasta que el conocimiento que es el resultado de la enseñanza ha encontrado un lugar en el alma de cada uno. $Y$ así estos detalles, aunque en verdad no podría decirse que fueran secretos, sí podía decirse que era imposible exponerlos de antemano, porque cuando se les expusiera no tendrian significación alguna." 76

Sin embargo, la clara comprensión de su misión hará que el Consejo Nocturno, el Instituto de Investigación del Valor proyectado por Platón, adelante con certidumbre. La primera tarea, encontrar la naturaleza del valor del uno y de los muchos, significa que tiene que hallarse una relacion entre las matemáticas del infinito y la naturaleza del valor.

La segunda tarea, o sea la de encontrar la naturaleza del valor de clasificación, significa que es necesario encontrar una relación entre la lógica de la clasificación y la naturaleza del valor. Ambas tareas implican que la naturaleza del valor tiene que encontrarse en relaciones formales y no empíricas. Esta comprensión necesita ser el punto de partida del Instituto de Investigación. En otras palabrás, como lo ha expresado acertadamente Cornford, el

71 Leyes, 965.

72 Leyes, 966.

73 Sofista, 253 F, G.

74 Sofista, 254 A.

75 Repriblica, VI, $5^{11} \mathrm{C}$

76 Leyes, 968 A, E. 
pensador que ha llegado a la definición de alguna Forma moral particular "tiene todavía tan sólo una parte de conocimiento. Necesita subir todavía más, hasta la Idea suprema en el terreno moral, y definir la naturaleza del Bien. Solamente entonces se verá la completa significación de la verdad descubierta en su relación con el resto de la verdad. Si se detiene, sus definiciones de Justicia y de otras Ideas, aun cuando sean correctas, serán análogas a una hipótesis matemática que es verdad pero que espera deducción del pri-

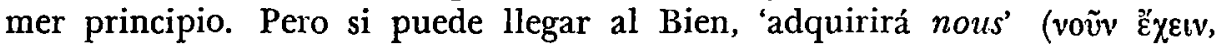
República, 534 B) esa visión iluminada de todo el campo que sólo puede tenerse desde la cima". 77

Solamente cuando se ha llegado a esa cima se habrá llegado al completo conocimiento dialéctico del valor. Las definiciones éticas inconexas "pueden alcanzar una comprensión de cualquier número de Formas morales sin relación entre ellas, pero no pueden conseguir la completa certidumbre ética". ${ }^{78}$ La cual puede lograrse solamente cuando las "Formas se vean, tanto en relación de unas con otras, como en relación con el origen de todas ellas, el Bien".79

En otras palabras, los valores específicos - moral, estético, legal y otrosno pueden comprenderse a menos que se defina el Valor mismo, y que se le defina de una manera completamente formal para que pueda aplicarse a cualquier valor especifico; y de una manera completamente sistemática para que todos los valores específicos puedan estar relacionados entre sí.

Cuando se haya hecho esto -y se haya resuelto el problema formal del valor, o sea la correlación de las formas de valor- el Instituto podrá continuar hacia la tarea penúltima y preguntar cómo las cuatro puedan ser una y sin embargo seguir siendo cuatro. Este problema se resuelve por sí solo e inmediatamente cuando se da la definición formal y sistemática de Valor. Porque entonces las cuatro aretai aparecerán claramente como lo que son -y como Platón indica que son-, es decir, "ilustraciones; y esto fue porque [sus] definiciones fueron formuladas más bien en términos empíricos (es decir, los términos del mundo físico) que como lo justificaría la realización pura de una Forma". ${ }^{80}$ Una vez que haya sido definida final y sistemáticamente la forma del valor, la naturaleza exacta de las aretai como ejemplos o aplicaciones de la misma se volverá clara. "La articulación de todas las Formas morales y sus derivaciones del Bien" 81 será entonces comprendida. "Todo se encuentra relacionado, a todo se le da su verdadera perspectiva; la certeza

77 F. M. Cornford, "Mathematics and Dialectic in the Republic, VI-VII", Mind N.S.

XLI (1932), p. 183; Gould, op. cit., p. 178.

78 Gould, ibid.

79 Ibid.

80 Gould, op. cit., p. 179 .

81 Ibid. 
descansa al fin sobre la comprensión del conjunto de la realidad moral." 82 Ha llegado la ciencia del valor.

Así, éste es el legado de Platón. En tanto que, a través de la historia de la filosofía moral, el contenido empírico de la ética se presentó en los datos de la vida moral, la estructura formal de referencia siguió tan oscura después de Platón como se encontraba antes. Mientras que Aristóteles podía usar los elementos empíricos de los diálogos, no podía asimilar los elementos formales. La relación entre el número y el Bien y entre la clasificación y lo bueno ha quedado tan oscura hasta hoy como lo era para Aristóteles. Pero la relación entre el número y la clasificación quedó al fin aclarada, en la obra de Frege y de Bertrand Russell. De esta manera se dieron las condiciones para una teoría de valor que pueda realizar el programa platónico.

Todos los temas de la teoría del valor han sido tratados por Platón. La solución nominalista señalaba una lógica de nombres como el marco de referencia para el valor, la solución realista señalaba a las matemáticas, y la solución empírica señalaba una vez más a la lógica, ahora ya como un sistema elaborado. Ni la lógica ni las matemáticas existían en tiempo de Platón como estructuras formales elaboradas. Por lo mismo, la ética avanzaba en la tercera dirección, o sea la empírica, pero sin la estructura sistemática elaborada que Platón tenía en mente para ella; y asi lo hacía de una manera seudo-científica y al acaso - o continuaba en la dirección metafísica, pero sin pasar más allá de las formulaciones platónico-socráticas del mito y de la metáfora- aún después de que la lógica y las matemáticas habían comenzado a desarrollarse. Así, el trabajo de construir una ciencia del valor con el material sacado de la lógica y de las matemáticas, aducido por Platón, se encuentra todavía ante nosotros.

Robert S. Hartman

82 Ibid. Leyes, 887 C, D. Consúltese Fedro, 270 C; Lutoslawski, op. cit., pág. $5^{1 x .}$ 